DALLACORT, Luis Ângelo; LUZ, Ariane Faverzani da; PILAU SOBRINHO, Liton Lanes. O transconstitucionalismo como uma alternativa para a problemática ambiental nas sociedades modernas. Revista Eletrônica Direito e Política, Programa de Pós-Graduação Stricto Sensu em Ciência Jurídica da UNIVALI, Itajaí, v.15, n.3, $3^{\circ}$ quadrimestre de 2020. Disponível em: www.univali.br/direitoepolitica - ISSN 1980-7791

\title{
O TRANSCONSTITUCIONALISMO COMO UMA ALTERNATIVA PARA A PROBLEMÁTICA AMBIENTAL NAS SOCIEDADES MODERNAS
}

\author{
TRANSCONSTITUTIONALISM AS AN ALTERNATIVE FOR ENVIRONMENTAL \\ PROBLEMS IN MODERN SOCIETIES
}

\author{
Luis Ângelo Dallacort ${ }^{1}$ \\ Ariane Faverzani da Luz $^{2}$ \\ Liton Lanes Pilau Sobrinho ${ }^{3}$
}

\section{RESUMO}

O presente estudo tem como objetivo analisar o fenômeno do transconstitucionalismo como forma de solução de demandas ambientais. Para isso, a pesquisa aborda conceitos sobre globalização e sociedades modernas. Também, abarca a questão ambiental no tocante à utilização de recursos naturais de maneira descontrolada e como essas ações comprometem o futuro da humanidade. Por fim, trata sobre o transconstitucionalismo como solução das problemáticas ambientais. Assim, utilizando-se do escopo teórico-bibliográfico e do método hipotético-dedutivo, os resultados obtidos indicaram a importância do diálogo entre distintos âmbitos jurídicos para a efetivação da conscientização universal em busca de uma sociedade mais equilibrada e sustentável.

PALAVRAS-CHAVE: Globalização; Meio Ambiente; Sustentatiblidade; Transconstitucionalismo.

\footnotetext{
${ }^{1}$ Mestrando em Direito pela Universidade de Passo Fundo (UPF) com auxílio CAPES. Pós-graduado em Direito do Trabalho pela Universidade do Vale do Itajaí (UNIVALI). Graduado em Direito pela Universidade de Passo Fundo (UPF). Advogado. Passo Fundo, Rio Grande do Sul, Brasil. E-mail: luisdallacort92@gmail.com.

2 Mestranda em Direito pela Universidade de Passo Fundo (UPF) com auxílio CAPES. Especialista em Direito Público pela Fundação Escola Superior do Ministério Público do Rio Grande do Sul (FMPRS). Especialista em Ciências Criminais pela Fundação Escola Superior do Ministério Público do Rio Grande do Sul (FMP-RS). Especialista em Direito Civil e Processo Civil pela Faculdade Meridional (IMED). Graduada em Direito pela Faculdade Meridional (IMED). Advogada. Passo Fundo, Rio Grande do Sul, Brasil. E-mail: arianefaverzani@outlook.com.

3 Professor dos cursos de Mestrado e Doutorado no Programa de Pós-Graduação Stricto Sensu em Ciência Jurídica da Universidade do Vale do Itajaí. Professor do Programa de Pós-Graduação Stricto Sensu Mestrado em Direito da Universidade de Passo Fundo. Coordenador do PPGDireito da Universidade de Passo Fundo. Pós-doutor em Direito pela Universidade de Sevilha - US. -Espanha. Doutor em Direito pela Universidade do Vale do Rio dos Sinos - UNISINOS (2008). Mestre em Direito pela Universidade de Santa Cruz do Sul - UNISC (2000). Possui graduação em Direito pela Universidade de Cruz Alta (1997). Passo Fundo, Rio Grande do Sul, Brasil. E-mail: liton@upf.br.
} 
DALLACORT, Luis Ângelo; LUZ, Ariane Faverzani da; PILAU SOBRINHO, Liton Lanes. O transconstitucionalismo como uma alternativa para a problemática ambiental nas sociedades modernas. Revista Eletrônica Direito e Política, Programa de Pós-Graduação Stricto Sensu em Ciência Jurídica da UNIVALI, Itajaí, v.15, n.3, 30 quadrimestre de 2020. Disponível em: www.univali.br/direitoepolitica - ISSN 1980-7791

\section{ABSTRACT}

The present study aims to analyze the phenomenon of transconstitutionalism as a way of solving environmental demands. For this, the research addresses concepts about globalization and modern societies. It also covers the environmental issue with regard to the uncontrolled use of natural resources and how these actions compromise the future of humanity. Finally, it deals with transconstitutionalism as a solution to environmental problems. Thus, using the theoretical-bibliographic scope and the hypothetical-deductive method, the results obtained indicated the importance of dialogue between different legal spheres for the realization of universal awareness in search of a more balanced and sustainable society.

KEYWORDS: Globalization; Environment; Sustainability; Transconstitutionalism.

\section{INTRODUÇÃO}

O direito ambiental vem ao longo dos anos crescendo de uma forma significativa tanto no cenário nacional quanto no internacional. Diante do avanço da exploração dos recursos naturais, mostrou-se imperativo buscar respostas à problemática ambiental. Por meio de acoplamentos de sistema, origina-se este ramo do direito, o qual pretende criar leis de caráter ambiental.

Para o desenvolvimento do presente artigo será realizada uma pesquisa de caráter bibliográfico, com o intuito de investigar de que maneira a teoria desenvolvida pelo professor Marcelo Neves, o Transconstitucionalismo, pode ajudar a enfrentar as problemáticas ambientais do século XXI.

Para tanto, o artigo será dividido em três tópicos. No primeiro, abordar-se-á a questão da globalização. Prefacialmente, serão destacados os impactos da globalização na sociedade contemporânea e como esta alterou de forma intensa a seara internacional, bem como as questões intrínsecas aos Estados. Por fim, será abordada a questão das sociedades mundiais, as quais apresentam uma construção social diferenciadas das que eram conhecidas no século passado, assim como a relativização das distâncias.

No tocante ao segundo capitulo, buscar-se-á dar enfoque à problemática ambiental, mencionando como essa questão está inteiramente interligada com o modo de produção trazido pelo capitalismo. Também, serão mencionados os esforços da sociedade internacional em buscar medidas efetivas de preservação. 
DALLACORT, Luis Ângelo; LUZ, Ariane Faverzani da; PILAU SOBRINHO, Liton Lanes. O transconstitucionalismo como uma alternativa para a problemática ambiental nas sociedades modernas. Revista Eletrônica Direito e Política, Programa de Pós-Graduação Stricto Sensu em Ciência Jurídica da UNIVALI, Itajaí, v.15, n.3, 30 quadrimestre de 2020. Disponível em: www.univali.br/direitoepolitica - ISSN 1980-7791

Ainda, irá ser abordado o princípio da cooperação entre os povos, que foi trazido por meio da Declaração da Conferencia das Nações Unidas sobre o Meio Ambiente Humano. Igualmente, será abordada a complexidade da questão Amazônica, onde incidem várias legislações internacionais sobre o meio ambiente, além da necessidade de se criar um pensamento conjunto entre todas as nações para a preservação do coração do mundo, isto é, a floresta amazônica.

No que se refere ao terceiro capítulo, será destacado o conceito de transconstitucionalismo, teoria trazida por Marcelo Neves, destacando sua relevância para a solução de situações nas sociedades modernas. Também, será apontado que esse fenômeno não tem como intuito a erradicação da soberania nacional, mas, sim, uma forma de diálogo e aprendizado com outros textos constitucionais. Além disso, será arguido de que forma o fenômeno do tranconsticionalismo pode ser uma solução eficaz para as dificuldades encontradas na regulamentação do direito ambiental.

\section{A GLOBALIZAÇÃO E AS SOCIEDADES EM REDE}

A sociedade está sofrendo, ao longo dos anos, alterações significativas. Uma das mais profundas mudanças, sem dúvida, é a globalização, a qual alterou de forma expressiva a realidade social, bem como a relação de soberania entre as nações. Dessa forma, novas problemáticas sociais surgem e lentamente alteram o cenário global, corroborando para o surgimento de sociedades interconectadas e dotadas de maior complexidade.

Assim, o presente capítulo busca fazer uma abordagem em relação ao panorama da globalização, destacando como este fenômeno modificou a sociedade e imprimiu a ela novos dilemas que, até então, eram desconhecidos, e que alteraram a história e as noções de tempo, de espaço e as relações que eram tidas como imutáveis.

De frente para as conquistas da humanidade, como as invenções, os primeiros meios de locomoção, a difusão do comércio, o avanço da tecnologia, o 
DALLACORT, Luis Ângelo; LUZ, Ariane Faverzani da; PILAU SOBRINHO, Liton Lanes. O transconstitucionalismo como uma alternativa para a problemática ambiental nas sociedades modernas. Revista Eletrônica Direito e Política, Programa de Pós-Graduação Stricto Sensu em Ciência Jurídica da UNIVALI, Itajaí, v.15, n.3, 30 quadrimestre de 2020. Disponível em: www.univali.br/direitoepolitica - ISSN 1980-7791

surgimento da internet e da facilidade em estabelecer contatos com outras nações, o processo de globalização se tornou mais palpável e impactante.

Para Barbosa ${ }^{4}$, poderia-se dizer que o surgimento de um sistema econômico mundial começava a surgir no final do século XV com o descobrimento da América, já que, em decorrência do avanço tecnológico nas construções dos meios de transporte, passou a ser possível o comércio entre as nações, o qual se deu por meio da circulação de mercadorias evoluindo para a produção de bens de consumo.

Embora já se esboçava séculos atrás uma relação entre nações, foi a partir da década de 80 que o mundo passou a experimentar uma maior conexão, passando a imprimir uma nova ideia das sociedades modernas. Para Marcelo Neves $^{5}$, as sociedades de caráter moderno são sociedades mundiais, as quais apresentam uma construção social desvinculadas de organizações políticas territoriais, apesar de estas, na forma de Estados, constituírem uma das dimensões fundamentais à sua reprodução. Conforme Bauman ${ }^{6}$

A 'globalização' está na ordem do dia; uma palavra da moda que se transforma rapidamente em um lema, uma encantação mágica, uma senha capaz de abrir as portas de todos os mistérios presentes e futuros. Para alguns, 'globalização' é o destino irremediável do mundo, um processo irreversível; é também um processo que nos afeta a todos na mesma medida e da mesma maneira. Estamos todos sendo 'globalizados' - e isso significa basicamente 0 mesmo para todos.

O processo de globalização possibilitou uma redução de distâncias entre nações, bem com facilitou as comunicações, relativizou as fronteiras geográficas e permitiu uma maior circulação de bens e pessoas. Assim, o mundo tal qual era conhecido algumas décadas atrás não mais existe. Para Bauman7, "as distâncias

\footnotetext{
4 BARBOSA, Alexandre de Freitas. O Mundo Globalizado: economia, sociedade e política. 5. ed. São Paulo: Contexto, 2010. p. 22-23.

${ }^{5}$ NEVES, Marcelo. Transconstitucionalismo. São Paulo: WMF Martins Fontes, 2009. p. 26.

${ }^{6}$ BAUMAN, Zygmunt. Globalização: as consequências humanas. Tradução de Marcus Penchel. Rio de Janeiro: Jorge Zahar Ed, 1999. p. 7.

7 BAUMAN, Zygmunt. Globalização: as consequências humanas. p. 20.
} 
DALLACORT, Luis Ângelo; LUZ, Ariane Faverzani da; PILAU SOBRINHO, Liton Lanes. O transconstitucionalismo como uma alternativa para a problemática ambiental nas sociedades modernas. Revista Eletrônica Direito e Política, Programa de Pós-Graduação Stricto Sensu em Ciência Jurídica da UNIVALI, Itajaí, v.15, n.3, 30 quadrimestre de 2020. Disponível em: www.univali.br/direitoepolitica - ISSN 1980-7791

já não importam, ao passo que a idéia de uma fronteira geográfica é cada vez mais difícil de sustentar no 'mundo real'".

Nesse caminho, Tomazette ${ }^{8}$ leciona que se deve usar o termo globalização de forma plural, uma vez que este fenômeno se dá nas mais diversas esferas sociais, desde questões relativas à economia, à cultura ou à política. Para tanto, argui o autor que não cabe reconhecer a globalização apenas como um fenômeno, mas, sim, como uma série destes.

Ao se analisar a aldeia global, a tomada de decisões em alguns países acabam repercutindo em outros, impactando seu meio ambiente e a economia, como, por exemplo, as decisões tomadas no Ocidente que afetam o Oriente e vice-versa. Diante desse cenário, percebe-se que as relações entre os seres humanos passaram a ser interconectadas. Tais processos criam uma interdependência sistêmica que deixam a humanidade refém de decisões de homens que detêm poder nos campos econômicos, políticos e bélicos.

Nesse sentido, leciona Giddens ${ }^{9}$ :

A globalização pode assim ser definida como a intensificação das relações sociais em escala mundial, que ligam localidades distantes de tal maneira que acontecimentos locais são modelados por eventos ocorrendo a muitas milhas de distância e vice-versa. Este é um processo dialético porque tais acontecimentos locais podem se deslocar numa direção anversa às relações muito distanciadas que os modelam. A transformação local é tanto uma parte da globalização quanto a extensão lateral das conexões sociais através do tempo e do espaço.

Para tanto, destaca-se que o fenômeno da globalização é um importante elemento de mudança, que apresentou situações até então desconhecidas na sociedade mundial. O mundo vem ao longo dos tempos apresentando novas tecnologias e novos agentes, flexibilizando as autonomias dos Estados e os

\footnotetext{
${ }^{8}$ TOMAZETTE, Marlon. Direito Societário e Globalização: rediscussão da lógica público-privada do direito societário diante das exigencias de um mercado global. São Paulo: Atlas, 2014. p. 3.

${ }^{9}$ GIDDENS, Anthony. As Consequências da Modernidade. Tradução de Raul Fiker. São Paulo: Unesp, 1991. p. 60.
} 
DALLACORT, Luis Ângelo; LUZ, Ariane Faverzani da; PILAU SOBRINHO, Liton Lanes. O transconstitucionalismo como uma alternativa para a problemática ambiental nas sociedades modernas. Revista Eletrônica Direito e Política, Programa de Pós-Graduação Stricto Sensu em Ciência Jurídica da UNIVALI, Itajaí, v.15, n.3, 30 quadrimestre de 2020. Disponível em: www.univali.br/direitoepolitica - ISSN 1980-7791

tornando impotentes. Assim, conforme leciona Beck ${ }^{10}$, a "globalización significa los procesos en virtud de los cuales los Estados nacionales soberanos se entre mezclan e imbrican mediante actores transnacionales y sus respectivas probabilidades de poder y orientaciones". Outro ponto que merece destaque são as duas facetas da globalização, pois é inegável que este fenômeno alterou o mundo, trazendo uma série de avanços sociais, políticos, econômicos, tecnológicos. Em contrapartida, também trouxe uma série de perdas, uma vez que relativiza as multiculturalidades, subtrai culturas milenares e impõem um modo de viver pautado no consumo e na insatisfação total. Desse modo, nas palavras de Bauman ${ }^{11}$ :

As quase soberanias, as divisões territoriais e a segregação de identidades promovidas e transformadas num must pela globalização dos mercados e da informação não refletem uma diversidade de parceiros iguais. O que é opção livre para alguns abate-se sobre outros como destino cruel.

Nesse tocante, evidencia-se que a globalização é um marco transformador que alterou paulatinamente a ordem mundial. A fábrica global "[...] provoca a desterritorialização e reterritorialização das coisas, gentes e idéias. Promove o redimensionamento de espaços e tempos"12.

Embora a globalização não tenha encerrado com o ideal de soberania dos Estados, aquela passou a relativizar este conceito, por meio do seu poder de interferências nos ordenamentos internos de cada nação. Assim, decisões governamentais necessitam observar questões externas ao seu território, buscando se alinhar a políticas econômicas e sociais internacionais.

Para fazer parte do mundo globalizado é primordial falar a mesma língua, assim, a soberania passa a coexistir com a necessidade de abertura da economia de cada país ${ }^{13}$, implicando no surgimento das chamadas sociedades globais. As

${ }^{10}$ BECK, Ulrich. ¿Qué es la globalización? Falacias del globalismo, respuestas a la globalización. Barcelona: Paidós, 2004. p. 29.

${ }^{11}$ BAUMAN, Zygmunt. Globalização: as consequências humanas. p. 78.

${ }^{12}$ IANNI, Octavio. Teorias da Globalização. Rio de Janeiro: Editora Civilização, 2002. p. 19.

13 ARAÚJO, Victor Costa de. O Transconstitucionalismo na Jurisprudência do Supremo Tribunal Federal: uma análise sob a ótica da teoria dos direitos fundamentais. Dissertação (Mestrado em Direito Público). Faculdade de Direito. Universidade Federal da Bahia. Salvador, 2015. p. 57. 
DALLACORT, Luis Ângelo; LUZ, Ariane Faverzani da; PILAU SOBRINHO, Liton Lanes. O transconstitucionalismo como uma alternativa para a problemática ambiental nas sociedades modernas. Revista Eletrônica Direito e Política, Programa de Pós-Graduação Stricto Sensu em Ciência Jurídica da UNIVALI, Itajaí, v.15, n.3, 30 quadrimestre de 2020. Disponível em: www.univali.br/direitoepolitica - ISSN 1980-7791

sociedades globais são aquelas que unem todas as sociedades, interligando-as de modo que uma depende da outra para existir.

Em relação a sua formação, as sociedades globais são compostas por diversidades culturais, politicas, econômicas e que se conectam de alguma forma. Tais sociedades não fazem com que ocorra extinção, nem a luta contra a cultura e as tradições de cada sociedade, todavia busca criar um elo entre os povos. Ademais, não possuem intenção de criar uma ordem jurídica única para todos os povos, - uma vez que busca respeitar a soberania de cada Estado e dos individuos que nele habitam-, mas, sim, busca promover uma maior interação entre os indivíduos que a compõem ${ }^{14}$.

Em decorrência do enredamento social existente e a pluralidade de situações distintas, foi essencial que o direito buscasse em outros campos da sapiência social respostas para questões de alto grau de complexidade. Hoje, a necessidade de dar respostas aos problemas de alta densidade é bem mais ampla do que no início do século passado. Assim, é preciso construir um pensamento amplo que seja capaz de garantir e dar soluções eficientes e rápidas a questões oriundas das redes globais, sendo que uma das mais urgentes é a questão ambiental, uma vez que esta é pertinente à humanidade.

\section{DIREITO AMBIENTAL E OS DESAFIOS DO SÉCULO XXI}

O direito ambiental, um novo ramo do direito, vem ganhando cada dia mais visibilidade, tendo em vista a necessidade de politicas públicas de preservação de recursos naturais e que possibilitem garantir a sobrevivência da população atual e das gerações futuras. Para tanto, o presente capítulo tem como finalidade abordar a temática ambiental e a necessidade de esforços conjuntos para a proteção do meio ambiente.

A sociedade moderna, composta de diversas pluralidades e com pretensões conflitantes entre si, estará condenada à própria autodestruição caso não consiga

14 ARAÚJO, Victor Costa de. O Transconstitucionalismo na Jurisprudência do Supremo

Tribunal Federal: uma análise sob a ótica da teoria dos direitos fundamentais. p. 59. 
DALLACORT, Luis Ângelo; LUZ, Ariane Faverzani da; PILAU SOBRINHO, Liton Lanes. O transconstitucionalismo como uma alternativa para a problemática ambiental nas sociedades modernas. Revista Eletrônica Direito e Política, Programa de Pós-Graduação Stricto Sensu em Ciência Jurídica da UNIVALI, Itajaí, v.15, n.3, 30 quadrimestre de 2020. Disponível em: www.univali.br/direitoepolitica - ISSN 1980-7791

criar fórmulas que permitissem o surgimento de relações construtivas de aprendizado e de influencia recíproca entre as diversas esferas sociais. Entretanto, não são suficientes métodos que permitam relações pontuais e momentáneas no plano das operações dos sistemas, os chamados 'acoplamentos operativos'. Faz-se necessário que existam vínculos estruturais que possibilitem as interinfluencias nas mais diversas esferas independentes de comunicação ${ }^{15}$. Nessa toada, Rocha e Scherbaum ${ }^{16}$ citam Luhmann:

Segundo Niklas Luhmann a Sociedade Mundial é
paradoxalmente, constituída por sistemas parciais
diferenciados funcionalmente, os quais, no entanto, detém
na comunicação o seu elemento último para a auto-
reprodução do sistema. Ou seja, a partir da universalização
da comunicação, como unidade de operação, que o sistema
social global se diferencia do ambiente (não sistema).

Assim, a comunicação do direito com as áreas relacionadas ao meio ambiente origina o direito ambiental, que é uma das respostas da sociedade ante sinais de desequilíbrio da natureza e a preocupação de existência de uma crise ambiental ${ }^{17}$. Para tanto, o direito ambiental tem como escopo regulamentar as relações do homem com o meio ambiente, buscando afastar o colapso mundial, além de evitar a chamada tragédia dos bens comuns, a qual Gordillo ${ }^{18}$ destaca que ocorre quando "[...] en un sistema de capitalismo de mercado los bienes que son de todos y cuyo uso es gratuito tienden a ser sobreutilizados y, por ello, devastado".

Inquestionável é a necessidade da existência de um ecossistema equilibrado para a efetivação da vida no planeta. Bilhões de mulheres e homens que vivem na

\footnotetext{
${ }^{15}$ NEVES, Marcelo. Transconstitucionalismo. São Paulo: WMF Martins Fontes, 2009. p. 34-35.

16 ROCHA, Leonel Severo; SCHERBAUM, Julia Francieli Neves de. O Manifesto da Transconstitucionalidade para a Preservação do Meio Ambiente. Revista Eletrônica do Curso de Direito da UFSM, Santa Maria, v. 14, n. 3, p. 1-32. 2019. p. 6.

17 FRANCO, José Gustavo de Oliveira. Direito Socioambiental e Desenvolvimento Sustentável: reflexões acerca do modelo de desenvolvimento Constitucionalmente adotado ante direitos humanos fundamentais. In: CENCI, Daniel Rubens; SCHONARDIE, Elenise Felzke (Orgs.). Direitos Humanos, Meio Ambiente e Novos Direitos. Ijuí: Unijuí, 2014. p. 49.
}

18 GORDILLO, José Luis Gordillo. A Vueltas con lo Común (a modo de presentación). In: GORDILLO, José Luis Gordillo (coord..). La Protección de Los Bienes Comunes de la Humanidad: un desafío para la política y el derecho del siglo XXI. Madrid: Trotta, 2006. p. 11-20. p. 11. 
DALLACORT, Luis Ângelo; LUZ, Ariane Faverzani da; PILAU SOBRINHO, Liton Lanes. O transconstitucionalismo como uma alternativa para a problemática ambiental nas sociedades modernas. Revista Eletrônica Direito e Política, Programa de Pós-Graduação Stricto Sensu em Ciência Jurídica da UNIVALI, Itajaí, v.15, n.3, 30 quadrimestre de 2020. Disponível em: www.univali.br/direitoepolitica - ISSN 1980-7791

Terra necessitam de um ambiente sadio e equilibrado para sua própria existência. A água, o ar, as matas, os pássaros, os insetos, entre tantos outros seres vivos, compõem o arranjo da vida, sendo indispensáveis para a preservação e continuação da humanidade.

Apesar de existir a necessidade do equilíbrio perfeito entre homem e natureza, sabe-se que o homem utiliza os recursos como se infindáveis fossem, acarretando no esgotamento precoce e impactando no futuro das próximas gerações. Neste sentido, Mateo ${ }^{19}$ menciona que "el hombre de hoy usa y abusa de la naturaleza como si hubiera de ser el último inquilino de este desgraciado planeta, como si detrás de él no se anunciara un futuro. La naturaleza se convierte así en el chivo expiatorio del progresso".

A partir da Revolução Industrial, os primeiros impactos ao meio ambiente foram sentidos. Resultado da acelerada produção de bens de consumo, os recursos passaram a ser explorados de forma descontrolada. Ademais, a falta de interesse em técnicas que evitassem a contaminação de solos e dos rios expôs a humanidade a uma grave situação. Desse modo, o homem passou a romper relações de trocas recíprocas que tinha com a natureza e passou a explora-lá de forma desmedida.

Como consequência da crise ambiental, foi fundamental rediscutir os paradigmas que impulsionaram o crescimento econômico em detrimento à natureza. Dessa forma, surge a sustentabilidade ecológica como um meio para a reconstrução de uma ordem política e econômica que seja capaz de garantir a sobrevivência humana e de alcançar um desenvolvimento duradouro ${ }^{20}$. O período do pósguerra foi um período de suma importância, visto que surgiram as primeiras grandes normas de proteção atinentes ao meio ambiente, as quais originaram o Direito Internacional do Meio Ambiente. Desse modo, o direito ao meio ambiente de qualidade se tornou um direito relativo à concretização do principio da dignidade da pessoa humana, sendo realizada em junho de 1992, na cidade do Rio de Janeiro, a Conferencia das Nações Unidas sobre Meio Ambiente e

\footnotetext{
19 MATEO, Ramón Martín. Tratado de Derecho Ambiental. Madrid: Trivium, 1991. p. 27.

20 LEFF, Enrique. Saber ambiental: sustentabilidade, racionalidade, complexidade, poder. Petrópolis, RJ: Vozes, 2001. p. 15.
} 
DALLACORT, Luis Ângelo; LUZ, Ariane Faverzani da; PILAU SOBRINHO, Liton Lanes. O transconstitucionalismo como uma alternativa para a problemática ambiental nas sociedades modernas. Revista Eletrônica Direito e Política, Programa de Pós-Graduação Stricto Sensu em Ciência Jurídica da UNIVALI, Itajaí, v.15, n.3, 30 quadrimestre de 2020. Disponível em: www.univali.br/direitoepolitica - ISSN 1980-7791

Desenvolvimento a fim de discutir a importância da preservação ambiental e da garantia de um ambiente sadio ${ }^{21}$.

Em âmbito nacional, a proteção do meio ambiente foi trazida pelo texto constitucional de 1988 como um dos direitos basilares, estando prevista no artigo 170, inciso VI. Também, no texto constitucional, o caput do artigo 225 da Constituição Federal de $1988^{22}$ define o direito ao meio ambiente equilibrado como um "direito de todos", logo, subjetivamente exigível por toda e qualquer pessoa ${ }^{23}$.

Em decorrencia de todas as respostas que são dadas pelo poder público, constata-se que surgiu uma preocupação em relação à elaboração de politicas públicas voltadas para a garantia de um sistema ambiental capaz de fornecer recursos indispensáveis à existência humana, bem como às futuras gerações.

Como consequência desse cenário, nasce o princípio da sustentabilidade que se tornou o objetivo central quando se abarca a temática relacionada aos recursos ambientais. Nesse caminho, leciona Leff ${ }^{24}$ :

O princípio de sustentabilidade surge no contexto da globalização como a marca de um limite e o sinal que reorienta o processo civilizatório da humanidade. A crise ambiental veio questionar a racionalidade e os paradigmas teóricos que impulsionaram e legitimaram o crescimento económico, negando a natureza. A sustentabilidade ecológica aparece assim como um critério normativo para a reconstrução da ordem económica, como uma condição para a sobrevivência humana e um suporte.

Nesse sentido, Gomes e Ferreira ${ }^{25}$ destacam a importância de um pensamento sustentável. Para os autores, a sustentabilidade se dá nas dimensões sociais,

\footnotetext{
${ }^{21}$ MAZZUOLI, Valério de Oliveira. A Proteção Internacional dos Direitos Humanos e o Direito Internacional do meio ambiente. Revista do Programa de Mestrado em Ciéncia Jurídica da Fundinopi. Jacarezinho, n. 9, p. 159-186. Jul./dez. 2008. p. 167.

22 BRASIL. Constituição da República Federativa do Brasil de 1988. Disponível em: http://www.planalto.gov.br/ccivil_03/constituicao/constituicao.htm. Acesso em: 15 set. 2019.

${ }^{23}$ ANTUNES, Paulo de Bessa. Direito Ambiental. 20. ed. São Paulo: Atlas, 2019. p. 11-12.

${ }^{24}$ LEFF, Enrique. Saber ambiental: sustentabilidade, racionalidade, complexidade, poder. p. 15.

25 GOMES, Magno Federici; FERREIRA, Leandro José. A Dimensão Jurídico-política da Sustentabilidade e o Direito Fundamental à Razoável Duração do Procedimento. Revista do Direito, Santa Cruz do Sul, v. 2, n. 52, p. 93-111. Out. 2017. p. 95.
} 
DALLACORT, Luis Ângelo; LUZ, Ariane Faverzani da; PILAU SOBRINHO, Liton Lanes. O transconstitucionalismo como uma alternativa para a problemática ambiental nas sociedades modernas. Revista Eletrônica Direito e Política, Programa de Pós-Graduação Stricto Sensu em Ciência Jurídica da UNIVALI, Itajaí, v.15, n.3, 30 quadrimestre de 2020. Disponível em: www.univali.br/direitoepolitica - ISSN 1980-7791

econômicas e éticas. Assim, na dimensão social mostra a necessidade de um pensamento que se preocupe com a qualidade de vida do ser humano, em virtude de que é intrínseca a relação dele com a natureza. Quanto à questão econômica, os autores destacam que na sustentabilidade o fator econômico não pode ser tratado com indiferença ou ser deixado de lado, já que são necessárias condições econômicas que possam permitir o pleno desenvolvimento sustentável nos padrões da sustentabilidade. Sobre a dimensão ética da sustentabilidade, esta se encontra diretamente conectada com a relação da justiça intergeracional. Assim, a presente geração é responsável pela herança ambiental e social que será deixada para as futuras gerações.

A existência de legislações ambientais é de suma importância, pois onde estas não existem certamente ocorrerão danos ambientais capazes de acarretar doenças, afetando uma alto contigente populacional. Salienta-se que as contaminações produzidas em certa região acabam por impactar outras áreas do planeta por meio da água, do ar, das chuvas ácidas, comprometendo a qualidade das vidas ${ }^{26}$.

Para Neves ${ }^{27}$, a degradação ambiental local acarreta problemas em todo o globo terrestre, ocasionando danos ambientais para uma pluralidade de ordens jurídicas que repercutem como um problema de caráter constitucional e com conjectura internacional.

Evidencia-se, portanto, o caráter global do meio ambiente, visto que este, tal qual a globalização, desconhece fronteiras, sendo incontrolável. Por isso, a importância de políticas mundiais de proteção, sendo urgente um esforço de todos os Estados, na busca pela proteção ao meio ambiente.

Diante da tomada de consciência da necessidade de preservar e proteger os recursos naturais, despertou nos órgãos públicos nacionais e internacionais a ideia da existência de um único meio ambiente, sendo preciso unificar esforços de poderes locais, nacionais, regionais, bem como a criação de normas de

26 PHILIPPI JR., Arlindo; ALVES, Alaôr Caffé; ROMÉRO, Marcelo de Andrade; BRUNA, Gilda Collet (ed.). Meio ambiente, Direito e Cidadania. São Paulo: Signus Editora, 2002. p. 28.

27 NEVES, Marcelo. Transconstitucionalismo. p. 298. 
DALLACORT, Luis Ângelo; LUZ, Ariane Faverzani da; PILAU SOBRINHO, Liton Lanes. O transconstitucionalismo como uma alternativa para a problemática ambiental nas sociedades modernas. Revista Eletrônica Direito e Política, Programa de Pós-Graduação Stricto Sensu em Ciência Jurídica da UNIVALI, Itajaí, v.15, n.3, 30 quadrimestre de 2020. Disponível em: www.univali.br/direitoepolitica - ISSN 1980-7791

conjuntura global, as quais permitissem evitar a proliferação de grandes tragédias ambientais ${ }^{28}$.

Para tanto, é inescusável a criação de um senso solidário entre os povos com o intuito de construir mecanismos para a concretização de práticas que busquem garantir um meio ambiente equilibrado e saudável. Um dos importantes passos, nesse sentido, foi dado na conferência de Estocolmo, no ano de 1972, a qual trouxe na Declaração da Conferencia das Nações Unidas sobre o Meio Ambiente Humano ${ }^{29}$ o princípio da cooperação. Assim, no princípio 24 da Declaração ${ }^{30}$ ficou estabelecido que:

Todos os países, grandes e pequenos, devem ocupar-se com espírito e cooperação e em pé de igualdade das questões internacionais relativas à proteção e melhoramento do meio ambiente. É indispensável cooperar para controlar, evitar, reduzir e eliminar eficazmente os efeitos prejudiciais que as atividades que se realizem em qualquer esfera, possam Ter para o meio ambiente, mediante acordos multilaterais ou bilaterais, ou por outros meios apropriados, respeitados a soberania e os interesses de todos os estados.

Em que pese já no ano de 1972 ter surgido a ideia de uma cooperação entre povos, o senso de solidariedade é mínimo na atualidade. Dessa forma, é crucial ampliar os esforços de todas as nações em prol da construção de políticas públicas de preservação ambiental e de soluções para um menor impacto ambiental.

Todavia, muitas vezes as políticas públicas de certos países vão na contramão do desenvolvimento sustentável e acabam expondo a humanidade a situações de risco Assim, faz-se substancial a construção de uma ideia que vá além dos limites dos estados, buscando em legislações externas as respostas a situações

28 SOARES, Guido Fernando Silva. A Proteção Internacional do Meio Ambiente. Barueri: Manole, 2003. p. 30-40.

${ }^{29}$ ORGANIZAÇÃO DAS NAÇÕES UNIDAS. Declaração da Conferencia das Nações Unidas sobre o Meio Ambiente Humano. Organização das Nações Unidas, 1972. Disponível em: http://www.direitoshumanos.usp.br/index.php/Meio-Ambiente/declaracao-de-estocolmo-sobre-oambiente-humano.html. Acesso em: 13 set. 2019.

30 ORGANIZAÇÃO DAS NAÇÕES UNIDAS. Declaração da Conferencia das Nações Unidas sobre o Meio Ambiente Humano. 
DALLACORT, Luis Ângelo; LUZ, Ariane Faverzani da; PILAU SOBRINHO, Liton Lanes. O transconstitucionalismo como uma alternativa para a problemática ambiental nas sociedades modernas. Revista Eletrônica Direito e Política, Programa de Pós-Graduação Stricto Sensu em Ciência Jurídica da UNIVALI, Itajaí, v.15, n.3, 30 quadrimestre de 2020. Disponível em: www.univali.br/direitoepolitica - ISSN 1980-7791

complexas ou desconhecidas vinculadas a demandas sociais e a questões de proteção ao meio ambiente.

\section{TRANSCONSTITUCIONALISMO: UMA SOLUÇÃO PARA AS PROBLEMÁTICAS AMBIENTAIS}

Como consequência da pluralidade de situações e da interconexão do meio ambiente, seria impossível evitar que degradações ocorridas em certas regiões do planeta não trouxessem impactos a terras distantes daquelas em que o dano se efetivou. Para tanto, é importante buscar soluções para problemáticas ambientais de forma conjunta.

Nessa seara, o presente capítulo tem como intuito abordar a importância de um pensamento conjunto em relação à problemática ambiental. Embora existam inúmeras legislações, tanto na esfera nacional como na internacional que abordem as questões ambientais, estas se mostram insatisfatórias, visto que que não são efetivas no combate à destruição de recursos naturais que são dilacerados pela indústria do consumo. Para tanto, mostra-se mais que fundamental a adoção de uma ideia que transcenda a seara estatal e possa se apresentar como um meio de respostas às questões atinentes ao meio ambiente.

Em virtude de uma integração originária da globalização e com o surgimento da sociedade mundial, ocorreu uma corrosão dos problemas-caso jurídicoconstitucionais, os quais tornaram-se independentes do Estado. Tal problemática pode ser vislumbrada no meio ambiente e em relação ao desenvolvimento sustentável, uma vez que os efeitos da degradação ambiental facilmente passam a ser sentidos em todo o planeta, ocasionando danos ambientais para várias ordens jurídicas que ressoam como uma complicação de cunho constitucional perante um cenário internacional ${ }^{31}$.

Embora no Brasil exista a garantia, no artigo 225 da Constituição Federal ${ }^{32}$, de um meio ambiente equilibrado, bem como a necessidade de proteção para a

31 ROCHA, Leonel Severo; SCHERBAUM, Julia Francieli Neves de. O Manifesto da Transconstitucionalidade para a Preservação do Meio Ambiente. p. 25.

32 BRASIL. Constituição da República Federativa do Brasil de 1988. 
DALLACORT, Luis Ângelo; LUZ, Ariane Faverzani da; PILAU SOBRINHO, Liton Lanes. O transconstitucionalismo como uma alternativa para a problemática ambiental nas sociedades modernas. Revista Eletrônica Direito e Política, Programa de Pós-Graduação Stricto Sensu em Ciência Jurídica da UNIVALI, Itajaí, v.15, n.3, 30 quadrimestre de 2020. Disponível em: www.univali.br/direitoepolitica - ISSN 1980-7791

presente e para as futuras gerações, além da existência de inúmeras leis infraconstitucionais, estas são incapazes de oferecer soluções às questões ambientais nas complexas sociedades mundiais.

Exemplo da dificuldade em traçar normas de proteção ambiental se dá na floresta Amazônica, onde há incidencia de uma ampla diversidade de legislações internacionais, já que a floresta ocupa o Brasil, Peru, Colômbia, Bolívia, Equador, Suriname, Venezuela, Guiana e Guiana Francesa. As inúmeras legislações incidem no mesmo espaço que, embora não pertença ao mesmo Estado, integra o mesmo bioma, o qual necessita ser protegido como um todo.

A proteção ao bioma se mostra de suma importância, já que nele vivem mais de trinta milhões de espécies animais, assim como uma vasta diversidade de espécies de vegetais e micro-organismos. Também, conta com muitos rios, sendo o principal o rio Amazonas, os quais juntos formam a maior reserva de água doce de superfície disponível do mundo ${ }^{33}$.

Nesse diapasão, destaca-se a necessidade de uma força mútua para a preservação do "coração do mundo". Assim, um dos meios que vem se mostrando apto a dar uma solução a essa problemática é a ideia de Marcelo Neves $^{34}$, o qual propõe o transconstitucionalismo:

A questão é outra quando se trata de transconstitucionalismo. Nesse caso, o problema consiste em delinear as formas de relação entre ordens jurídicas diversas. Ou seja, dentro de um mesmo sistema funcional da sociedade mundial moderna, o direito, proliferam ordens jurídicas diferenciadas, subordinadas ao mesmo código binário, isto é, 'lícito/ilícito', mas com diversos programas e critérios. Verifica-se, dessa maneira, uma pluralidade de ordens jurídicas, cada uma das quais com seus próprios elementos ou operações (atos jurídicos), estruturas (normas jurídicas), processos (procedimentos jurídicos) e reflexão da identidade (dogmática jurídica).

33 MORAES, Denise. Bioma Amazônia. Invivo, 2019. Disponível em: http://www.invivo.fiocruz.br/cgi/cgilua.exe/sys/start.htm?infoid=958\&sid=2. Acesso em: 14 . set. 2019.

34 NEVES, Marcelo. Transconstitucionalismo. p. 115-116. 
DALLACORT, Luis Ângelo; LUZ, Ariane Faverzani da; PILAU SOBRINHO, Liton Lanes. O transconstitucionalismo como uma alternativa para a problemática ambiental nas sociedades modernas. Revista Eletrônica Direito e Política, Programa de Pós-Graduação Stricto Sensu em Ciência Jurídica da UNIVALI, Itajaí, v.15, n.3, 30 quadrimestre de 2020. Disponível em: www.univali.br/direitoepolitica - ISSN 1980-7791

A partir da premissa inicial, pode-se compreender o transconstitucionalismo como a existéncia de ordens jurídicas diversas, as quais versam sobre uma mesma pauta constitucional, buscando possibilitar uma comunicação entre estas ordens jurídicas e encontrar meio de fornecer respostas ante questões complexas, ou seja, trata-se de um constitucionalismo relacionado a problemáticas jurídico-constitucionais, que, de forma simultânea, aparecem em diversas ordens constitucionais ${ }^{35}$.

Em que pese existam diversas legislações nacionais e de caráter internacional na temática ambiental, estas não respondem de forma satisfatória aos problemas que o meio ambiente vem enfrentando, evidenciando a fragilidade do constitucionalismo do Estado ao encarar os sérios dilemas da sociedade mundial, não ofertando, quando considerados isoladamente, soluções adequadas para os problemas constitucionais do presente ${ }^{36}$.

Diante da dificuldade em encontrar remédios legislativos no ordenamento nacional capazes de solucionar as problemáticas ambientais, passa a ser necessário construir um diálogo com outras ordens jurídicas. Conquanto essa troca entre diversas ordens jurídicas aconteça, não ocorre a incidência de uma verticalidade de normas, isto é, não existe a imposição de uma sobre a outra, não sendo criada uma estrutura hierárquica de normas. Assim, o transconstitucionalismo pode ser visto como uma troca de informações, emergindo uma constitucionalidade cruzada.

Cumpre mencionar que o transconstitucionalismo não tem como escopo a ideia de uma "Constituição global", isto é, a criação de um único documento constitucional válido para os povos, a qual seja superior às Constituições dos Estados, mas, sim, o surgimento de um diálogo entre diferentes sistemas para o aperfeiçoamento e aprendizado recíprocos ${ }^{37}$.

Para tanto, mostra-se que as questões de cunho ambiental complexas podem encontrar em outros textos constitucionais alienígenas soluções para problemas

\footnotetext{
${ }^{35}$ NEVES, Marcelo. Transconstitucionalismo. p. 129.

${ }^{36}$ NEVES, Marcelo. Transconstitucionalismo. p. 131.

37 ARAÚjO, Victor Costa de. O Transconstitucionalismo na Jurisprudência do Supremo

Tribunal Federal: uma análise sob a ótica da teoria dos direitos fundamentais. p. 68.
} 
DALLACORT, Luis Ângelo; LUZ, Ariane Faverzani da; PILAU SOBRINHO, Liton Lanes. O transconstitucionalismo como uma alternativa para a problemática ambiental nas sociedades modernas. Revista Eletrônica Direito e Política, Programa de Pós-Graduação Stricto Sensu em Ciência Jurídica da UNIVALI, Itajaí, v.15, n.3, 30 quadrimestre de 2020. Disponível em: www.univali.br/direitoepolitica - ISSN 1980-7791

internos sem o comprometimento da soberania nacional, todavia com a inteligência de outros Estados, os quais já encontram soluções para dilemas semelhantes.

O planeta conta com mais de cem textos constitucionais que garantem o direito a um meio ambiente limpo e saudável, além da prevenção à ocorrência de danos ambientais e a proteção dos recursos naturais ${ }^{38}$. Assim, evidencia-se a preocupação das nações em desenvolver mecanismos que garantam o equilíbrio ambiental e a preservação desses recursos para as futuras gerações.

Nessa toada, é primordial que o Direito Constitucional vá além dos Estados para oferecer respostas a questões de caráter transconstitucionais, ultrapassando as fronteiras dos seus respectivos Estados, tornando-se relevante para outras ordens jurídicas estatais e até não-estatais não como uma constituição global,

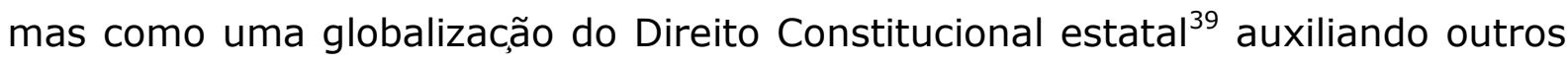
Estados em situações em que não detêm o conhecimento essencial.

Por meio do transconstitucionalismo, os Estados passam a encontrar soluções que enfrentam os impasses relacionados às problemáticas ambientais. Uma das soluções possíveis para o Brasil na seara do direito ambiental é buscar respaldo em outros países que já enfrentaram determinadas ocorrências e traçar um diálogo com estes.

Ainda que exista uma ampla legislação de direito ambiental em âmbito internacional, é no direito nacional dos países que se encontra a forca vinculante para proteção do meio ambiente. Sendo assim, é por meio de políticas públicas ambientais, de sanções administrativas e de decisões judiciais dos tribunais internos que as normas protetivas conquistam maior força coercitiva ${ }^{40}$.

Em que pese no âmbito interno de cada Estado deveria haver maior preocupação referente à temática dos direitos ambientais, muitas vezes, como vem ocorrendo

38 FITZMAURICE, Malgosia; M. ONG, David; MERKOURIS, Panos. Research Handbook on International Environmental Law. USA: Edward Elgar, 2010. p. 267.

${ }^{39}$ CUNHA JÚNIOR, Dirley. Curso de Direito Constitucional. 7 ed. Salvador: JusPodivm, 2013. p. 43-44.

40 AYALA, Patryck de Araújo; SILVEIRA, Paula Galbiatti. A Caracterização do Princípio de Sustentabilidade no Direito Brasileiro e o Transconstitucionalismo como Teoria de Efetivação.

Revista do Instituto de Direito Brasileiro, Lisboa, ano 1, n. 3, p. 1827-1859, 2010. p. 1851. 
DALLACORT, Luis Ângelo; LUZ, Ariane Faverzani da; PILAU SOBRINHO, Liton Lanes. O transconstitucionalismo como uma alternativa para a problemática ambiental nas sociedades modernas. Revista Eletrônica Direito e Política, Programa de Pós-Graduação Stricto Sensu em Ciência Jurídica da UNIVALI, Itajaí, v.15, n.3, 30 quadrimestre de 2020. Disponível em: www.univali.br/direitoepolitica - ISSN 1980-7791

no Brasil, são editadas normas de retrocesso, relativizando ou limitando as normas ambientais. Assim, o Direito Internacional se mostra como o meio mais efetivo para pressionar os agentes públicos quanto ao dever estatal e mundial de sustentabilidade ${ }^{41}$.

Por fim, é evidente o papel do Estado na proteção ambiental. No entanto, ante insuficiência da força vinculante das normas nacionais, além do retrocesso na temática ambiental, revela-se cada vez mais necessário os tribunais buscarem, por meio do transconstitucionalismo, estabelecer diálogos com outras ordens internacionais, pois somente desta maneira será possível uma maior proteção ao meio ambiente.

\section{CONSIDERAÇÕES FINAIS}

Ao realizar o presente estudo se buscou construir um pensamento sobre a importância do transconstitucionalismo para a construção de uma proteção mais efetiva dos recursos naturais. Diante da pluralidade de textos constitucionais, os quais têm uma preocupação com temáticas relacionadas ao meio ambiente, nota-se a relevância do tema na sociedade contemporânea.

Em virtude dos impactos ambientais de proporções avassaladoras, o mundo caminha a passos largos para uma extinção em massa tanto de recursos naturais como de seres vivos. Na atualidade, a inescrupulosa busca por poder econômico se tornou mais valiosa do que a vida de bilhões de pessoas, evidenciando-se uma troca de valores nunca antes vista. Desse modo, mostra-se imperativo explorar temáticas relevantes ao meio ambiente, buscando-se soluções capazes de diminuírem a degradação de recursos tão imprescindíveis para a existência humana.

Embora a globalização tenha alterado a sociedade e proporcionado uma maior proximidade entre os indivíduos, permitindo uma ampla facilidade de locomoção e de comunicações, ela também gerou uma sociedade mais complexa e dotada de peculiaridades, criando, assim, um enredamento social repleto de

41 AYALA, Patryck de Araújo; SILVeIRA, Paula Galbiatti. A Caracterização do Princípio de Sustentabilidade no Direito Brasileiro e o Transconstitucionalismo como Teoria de Efetivação. p. 1853. 
DALLACORT, Luis Ângelo; LUZ, Ariane Faverzani da; PILAU SOBRINHO, Liton Lanes. O transconstitucionalismo como uma alternativa para a problemática ambiental nas sociedades modernas. Revista Eletrônica Direito e Política, Programa de Pós-Graduação Stricto Sensu em Ciência Jurídica da UNIVALI, Itajaí, v.15, n.3, 30 quadrimestre de 2020. Disponível em: www.univali.br/direitoepolitica - ISSN 1980-7791

singularidades. Diante dessas características, torna-se necessário a adoção de um diálogo entre os atores globais a fim de solucionar as novas demandas sociais.

Vislumbra-se, assim, no tocante ao meio ambiente, a necessidade de diálogos transconstitucionais, capazes de maximizar as leis de proteção ambiental e, consequentemente, garantir a preservação na natureza. Para tanto, ainda que existam leis em âmbito nacional, estas não alcançam o resultado esperado, sendo necessário um aperfeiçoamento por meio de uma interligação de ordem jurídicas distintas.

O problema ambiental transcende fronteiras, não diferenciado ricos e pobres, negros os brancos, pois todos estão conectados de forma universal. O planeta já demonstrando sinais de saturação e assinalando para a humanidade a necessidade urgente de que medidas sejam tomadas a fim de evitar o seu declínio. Nesse sentido, faz-se imprescindível que se operem esforços coletivos das nações quanta à temática ambiental com o objetivo de promover uma conscientização universal a fim de uma sociedade mais equilibrada e sustentável.

\section{REFERÊNCIAS DAS FONTES CITADAS}

ARAÚJO, Victor Costa de. O Transconstitucionalismo na Jurisprudência do Supremo Tribunal Federal: uma análise sob a ótica da teoria dos direitos fundamentais. Dissertação (Mestrado em Direito Público). Faculdade de Direito. Universidade Federal da Bahia. Salvador, 2015.

ANTUNES, Paulo de Bessa. Direito Ambiental. 20. ed. São Paulo: Atlas, 2019.

AYALA, Patryck de Araújo; SILVEIRA, Paula Galbiatti. A Caracterização do Princípio de Sustentabilidade no Direito Brasileiro e o Transconstitucionalismo como Teoria de Efetivação. Revista do Instituto de Direito Brasileiro, Lisboa, ano 1, n. 3, p. 1827-1859, 2010.

BECK, Ulrich. ¿Qué es la globalización? Falacias del globalismo, respuestas a la globalización. Barcelona: Paidós, 2004.

BARBOSA, Alexandre de Freitas. O mundo globalizado: Economia, Sociedade e Política. 5. ed. São Paulo: Contexto, 2010.

BAUMAN, Zygmunt. Globalização: as consequências humanas. Tradução de Marcus Penchel. Rio de Janeiro: Jorge Zahar Ed, 1999. 
DALLACORT, Luis Ângelo; LUZ, Ariane Faverzani da; PILAU SOBRINHO, Liton Lanes. O transconstitucionalismo como uma alternativa para a problemática ambiental nas sociedades modernas. Revista Eletrônica Direito e Política, Programa de Pós-Graduação Stricto Sensu em Ciência Jurídica da UNIVALI, Itajaí, v.15, n.3, 30 quadrimestre de 2020. Disponível em: www.univali.br/direitoepolitica - ISSN 1980-7791

BRASIL. Constituição da República Federativa do Brasil de 1988. Disponível

em: http://www.planalto.gov.br/ccivil_03/constituicao/constituicao.htm. Acesso em: 15 set. 2019.

CUNHA JÚNIOR, Dirley. Curso de Direito Constitucional. 7 ed. Salvador: JusPodivm, 2013.

FITZMAURICE, Malgosia; M. ONG, David; MERKOURIS, Panos. Research Handbook on International Environmental Law. USA: Edward Elgar, 2010.

FRANCO, José Gustavo de Oliveira. Direito Socioambiental e Desenvolvimento Sustentável: reflexões acerca do modelo de desenvolvimento Constitucionalmente adotado ante direitos humanos fundamentais. In: CENCI, Daniel Rubens; SCHONARDIE, Elenise Felzke (Orgs.). Direitos Humanos, Meio Ambiente e Novos Direitos. Ijuí: Unijuí, 2014. GIDDENS, Anthony. As Consequências da Modernidade. Tradução de Raul Fiker. São Paulo: Unesp, 1991.

GORDILLO, José Luis Gordillo. A Vueltas con lo Común (a modo de presentación). In: GORDILLO, José Luis Gordillo (coord..). La Protección de Los Bienes Comunes de la Humanidad: un desafío para la política y el derecho del siglo XXI. Madrid: Trotta, 2006. p. 11-20.

GOMES, Magno Federici; FERREIRA, Leandro José. A Dimensão Jurídico-política da Sustentabilidade e o Direito Fundamental à Razoável Duração do Procedimento. Revista do Direito, Santa Cruz do Sul, v. 2, n. 52, p. 93-111. Out. 2017.

IANNI, Octavio. Teorias da Globalização. Rio de Janeiro: Editora Civilização, 2002.

LEFF, Enrique. Saber ambiental: sustentabilidade, racionalidade, complexidade, poder. Petrópolis, RJ: Vozes, 2001.

MATEO, Ramón Martín. Tratado de Derecho Ambiental. Madrid: Trivium, 1991.

MAZZUOLI, Valério de Oliveira. A Proteção Internacional dos Direitos Humanos e o Direito Internacional do meio ambiente. Revista do Programa de Mestrado em Ciencia Jurídica da Fundinopi. Jacarezinho, n. 9, p. 159-186. Jul./dez. 2008.

MORAES, Denise. Bioma Amazônia. Invivo, 2019. Disponível em: http://www. invivo. fiocruz. br/cgi/cgilua. exe/sys/start. htm?infoid=958\&sid=2. Acesso em: 14. set. 2019.

NEVES, Marcelo. Transconstitucionalismo. São Paulo: WMF Martins Fontes, 2009. 
DALLACORT, Luis Ângelo; LUZ, Ariane Faverzani da; PILAU SOBRINHO, Liton Lanes. O transconstitucionalismo como uma alternativa para a problemática ambiental nas sociedades modernas. Revista Eletrônica Direito e Política, Programa de Pós-Graduação Stricto Sensu em Ciência Jurídica da UNIVALI, Itajaí, v.15, n.3, 30 quadrimestre de 2020. Disponível em: www.univali.br/direitoepolitica - ISSN 1980-7791

ORGANIZAÇÃO DAS NAÇÕES UNIDAS. Declaração da Conferencia das Naç̃̃es Unidas sobre o Meio Ambiente Humano. Organização das Nações Unidas, 1972. Disponível em: http://www.direitoshumanos.usp.br/index.php/MeioAmbiente/declaracao-de-estocolmo-sobre-o-ambiente-humano.html. Acesso em: 13 set. 2019.

PHILIPPI JR., Arlindo; ALVES, Alaôr Caffé; ROMÉRO, Marcelo de Andrade; BRUNA, Gilda Collet (ed.). Meio ambiente, Direito e Cidadania. São Paulo: Signus Editora, 2002.

ROCHA, Leonel Severo; SCHERBAUM, Julia Francieli Neves de. O Manifesto da Transconstitucionalidade para a Preservação do Meio Ambiente. Revista Eletrônica do Curso de Direito da UFSM, Santa Maria, v. 14, n. 3, p. 1-32. 2019.

SOARES, Guido Fernando Silva. A Proteção Internacional do Meio Ambiente. Barueri: Manole, 2003.

TOMAZETTE, Marlon. Direito Societário e Globalização: rediscussão da lógica público-privada do direito societário diante das exigencias de um mercado global. São Paulo: Atlas, 2014. 